\title{
Mixing of mineral dust with urban pollution aerosol over Dakar (Senegal): impact on dust physico-chemical and radiative properties
}

\author{
By A. PETZOLD ${ }^{1 *}, A . \operatorname{VEIRA}^{1}, \mathrm{~S} . \mathrm{MUND}^{1}, \mathrm{M} . \mathrm{ESSELBORN}^{1}, \mathrm{C} . \mathrm{KIEMLE}^{1}, \mathrm{~B} . \mathrm{WEINZIERL}^{1}$, \\ T. HAMBURGER ${ }^{1}$, G. EHRET ${ }^{1}, \mathrm{~K}_{\text {. LIEKE }}{ }^{2}$ and K. KANDLER ${ }^{2},{ }^{1}$ Institut für Physik der Atmosphäre, \\ Deutsches Zentrum für Luft- und Raumfahrt Oberpfaffenhofen, 82234 Wessling, Germany; ${ }^{2}$ Institut für Angewandte \\ Geowissenschaften, Technische Universität Darmstadt, Schnittspahnstraße 9, 64287 Darmstadt, Germany
}

(Manuscript received 19 December 2010; in final form 9 May 2011)

\begin{abstract}
In the framework of the Saharan Mineral Dust Experiment (SAMUM) in 2008, the mixing of the urban pollution plume of Dakar (Senegal) with mineral dust was studied in detail using the German research aircraft Falcon which was equipped with a nadir-looking high spectral resolution lidar (HSRL) and extensive aerosol in situ instrumentation. The mineral dust layer as well as the urban pollution plume were probed remotely by the HSRL and in situ. Back trajectory analyses were used to attribute aerosol samples to source regions. We found that the emission from the region of Dakar increased the aerosol optical depth $(532 \mathrm{~nm}$ ) from approximately 0.30 over sea and over land east of Dakar to 0.35 in the city outflow. In the urban area, local black carbon (BC) emissions, or soot respectively, contributed more than $75 \%$ to aerosol absorption at $530 \mathrm{~nm}$. In the dust layer, the single-scattering albedo at $530 \mathrm{~nm}$ was $0.96-0.99$, whereas we found a value of $0.908 \pm 0.018$ for the aerosol dominated by urban pollution. After $6 \mathrm{~h}$ of transport over the North Atlantic, the externally mixed mode of secondary aerosol particles had almost completely vanished, whereas the BC agglomerates (soot) were still externally mixed with mineral dust particles.
\end{abstract}

\section{Introduction}

Mineral dust (MD) and light-absorbing black carbon (BC), or soot, respectively, are the two dominant light-absorbing components of the tropospheric aerosol. The spectral dependence of the light absorbing properties differs significantly between MD and BC. Dust is characterized by strong light absorption in the blue and green spectral range (Sokolik and Toon, 1996), whereas $\mathrm{BC}$ absorbs efficiently in the entire visible spectral region (Bond and Bergstrom, 2006). Mixing MD with BC may thus impact the radiative properties of MD significantly (Fuller et al., 1999; Forster et al., 2007).

Radiative properties of fresh MD and of dust mixed with anthropogenic pollution such as $\mathrm{BC}$ are in the focus of current research for two reasons: first, deserts are by far the strongest sources for airborne particulate matter on a global scale representing about half of the annual particle emission at the global scale (Forster et al., 2007), and second, driven by growing

\footnotetext{
* Corresponding author. e-mail: andreas.petzold@dlr.de DOI: $10.1111 / \mathrm{j} .1600-0889.2011 .00547 . \mathrm{x}$
}

megacities in arid areas the impact of anthropogenic pollution on the physico-chemical properties of MD becomes more and more relevant. Particularly in Asia, densely populated and thus heavily polluted areas are quite frequently located close to strong sources of MD, causing intense mixing of dust and anthropogenic pollution.

Mixing of dust with other particulate matter is expected to include sea salt, BC and primary biological particles such as micro-organisms, for example (Zhang et al., 2006; Formenti et al., 2008; Rajot et al., 2008; Hand et al., 2010). In addition, many dust particles contain sulphates or nitrates, which are formed by heterogeneous reactions involving sulphur dioxide and nitrogen oxides (Trochkine et al., 2003; Zhang et al., 2003; Putaud et al., 2004).

The mixing of dust with anthropogenic pollution from industrialized areas was investigated in several studies for the outflow regimes of Asian (Parungo et al., 1994; Clarke et al., 2004; Quinn et al., 2004) or African (Kandler et al., 2007; Chou et al., 2008) arid areas and deserts. In these studies, samples were collected hours to days away from the source region, giving sufficient time for efficient mixing of the aerosol. In the majority of investigated cases, these studies indicate the confinement of $\mathrm{BC}$ particles to 
the sub-micrometre size range. However, microscopy analyses of single particles (Quinn et al., 2004) as well as the analysis of absorption spectra (Clarke et al., 2004) show direct evidence for supermicron dust-BC aerosol mixtures after several hours to days of atmospheric processing. Similar observations are reported for internal mixtures of biomass burning aerosol and MD (Hand et al., 2010).

Studies on the mixing of anthropogenic pollution and MD in the vicinity of heavily populated regions were almost exclusively conducted in Asia. In samples taken during a Beijing dust storm $\mathrm{BC}$ aggregates were found predominantly in the size range $d_{\mathrm{p}}<0.6 \mu \mathrm{m}$ with a maximum abundance in $0.2 \mu \mathrm{m}<d_{\mathrm{p}}<$ $0.3 \mu \mathrm{m}$ (Shi et al., 2003). Results from a flight mission during ACE-Asia downwind Beijing (Song et al., 2005) showed that $90 \%$ of the MD particles were almost pure, not being significantly affected by, or interacting with, anthropogenic pollutants. In the East Asian Study of Tropospheric Aerosols (EAST-AIRE) near Beijing heavily polluted air mass mixed occasionally with MD (Yang et al., 2009). During dust events, a higher percentage of the carbonaceous mass was found in the coarse mode than during periods dominated by anthropogenic pollution, suggesting a possible surface adsorption mechanism of $\mathrm{BC}$ onto dust particles.

Observations of the dust fine mode single-scattering albedo at a wavelength of $550 \mathrm{~nm}$ off the coast of Senegal indicate values of 0.96-0.97 (Haywood et al., 2003) whereas earlier measurements provided a value of 0.87 (Haywood et al., 2001). The lower value is likely being caused by mixing with absorbing biomassburning aerosol. Pointing in the same direction, dust coated with carbonaceous aerosol observed during ACE-Asia also leads to increased absorption of solar radiation (Bergstrom et al., 2004). EAST-AIRE (Yang et al., 2009) reports single-scattering albedo values $(550 \mathrm{~nm})$ of $0.90 \pm 0.04$ for dust and $0.80 \pm 0.05$ for polluted air masses. In the outflow of Japan, Shanghai and Korea, single-scattering albedo values of 0.90-0.95 were found while during dust events values were $>0.95$ (Quinn et al., 2004). Measurements of the imaginary part of the dust refractive index over the Moroccan desert and in the vicinity of Casablanca also clearly show a strong impact of soot mixing with dust (Petzold et al., 2009).

Because systematic studies close to anthropogenic source regions in particular for the Saharan desert are still sparse, the mixing of urban pollution and dust was investigated as part of SAMUM-2 (Ansmann et al., 2011). A case study was performed over Dakar, Senegal, on 29 January 2008 during a strong Saharan dust outbreak. The MD layer as well as the urban pollution plume were probed by means of an airborne lidar system as well as by airborne in situ measurements upstream the source region, right over the source and finally in the outflow regime over the North Atlantic. Key objectives tackled by the study were the modification of the dust aerosol optical depth (AOD) and the change in dust aerosol size distributions, mixing state and chemical composition caused by the anthropogenic emissions.

\section{Experimental approaches}

Dakar is the capital of the West African state Senegal. The city centre is situated on the Cape Verde peninsula at the North Atlantic coastline. At the beginning of 2010, the population of Dakar region was 2.675 million people, placing Dakar on rank 19 of the largest cities in Africa. The location on a peninsula with no major urban agglomerations in its proximity as well as the population density make Dakar an ideal city for studying the mixing of urban emissions with MD.

\subsection{Measurement platform}

The measurements described in the following sections were conducted with the Falcon research aircraft operated by the Deutsches Zentrum für Luft- und Raumfahrt (DLR). The instrumentation was similar to the experiment SAMUM-1 (Esselborn et al., 2009; Petzold et al., 2009; Weinzierl et al., 2009). The payload combined a nadir-looking high spectral resolution lidar (HSRL) for the measurement of aerosol extinction at $532 \mathrm{~nm}$ (Esselborn et al., 2008), with extensive aerosol microphysics and chemistry in situ instruments which covered the whole particle diameter spectrum from the smallest nucleation mode particles at $4 \mathrm{~nm}$ to large MD particles in the far super-micrometre range. The Falcon standard instrumentation provided data for atmospheric parameters such as temperature, pressure, relative humidity and 3-D wind velocity. For a detailed description of the aerosol microphysical properties measured by the Falcon, refer to (Petzold et al., 2009; Weinzierl et al., 2009).

The sub-100 nm particle fraction was sized by a set of condensation particle counters (CPC), which were operated at different cut-off diameters. The different cut-off diameters were partly accomplished by a modification of the instruments supersaturation ratio and partly by a combination of the $\mathrm{CPC}$ with diffusion screen separators (Feldpausch et al., 2006). The super-100 nm particle fraction was sized by a combination of optical particle counters (OPC) of type Grimm 1.109, PCASP-100X, FSSP300 and FSSP-100. A Differential Mobility Analyser (DMA) was operated in a stepping mode at diameters 0.015, 0.03, 0.05, $0.08,0.12$ and $0.16 \mu \mathrm{m}$.

Beyond particle sizing, the aerosol absorption coefficients were measured at wavelengths of 467, 530 and $660 \mathrm{~nm}$ by means of a $3-\lambda$ particle soot absorption photometer (PSAP; Virkkula et al., 2005) and an additional $1-\lambda$ PSAP operated at $530 \mathrm{~nm}$. The CPC, DMA, one of the OPC (Grimm 1.109) and the 3- $\lambda$ PSAP were connected to an aerosol inlet which allowed for sampling in the approximate size range $d_{\mathrm{p}}<3.0 \mu \mathrm{m}$ at low altitude. The $1-\lambda$ PSAP was connected to a different inlet, which allowed only sub-micrometre sized particles to enter the instrument. The difference between the absorption by particles with either $d_{\mathrm{p}}<$ $3.0 \mu \mathrm{m}$ or $d_{\mathrm{p}}<1.0 \mu \mathrm{m}$ provides information on which fraction of the aerosol absorption is contributed by the coarse mode aerosol. 
The 3- $\lambda$ PSAP data were combined with the inlet-corrected size distributions measured by the PCASP. We then used this data to determine the complex refractive index of desert dust, urban pollution aerosol and marine aerosol particles (Petzold et al., 2009 ). Based on the $3-\lambda$ PSAP correction scheme (Virkkula, 2010), the applied data analysis algorithm simulates the response of the 3- $\lambda$ PSAP to the sampled aerosol. Absorption and scattering coefficients are calculated from the size distribution measured by the PCASP. The complex refractive index is optimized in an iterative process to match the instrument responses at all three wavelengths within a deviation of $3 \%$. Based on the optimized refractive index, the sampled particulate matter (PM) is modelled as a linear combination of a solely lightscattering component $\left(\mathrm{SiO}_{2}\right)$, one light-absorbing component with a strong spectral dependence of the absorption spectrum (hematite, $\mathrm{Fe}_{2} \mathrm{O}_{3}$ ), and another light-absorbing component with a spectrally flat absorption spectrum (BC), that is $\mathrm{PM}=\alpha \times$ $\left[\mathrm{SiO}_{2}\right]+\beta \times\left[\mathrm{Fe}_{2} \mathrm{O}_{3}\right]+\gamma \times[\mathrm{BC}]$. Symbols $\alpha, \beta$ and $\gamma$ refer to the respective volume fractions. Details of the method are given by Petzold et al. (2009). Relative uncertainties in the determination of the imaginary part of the refractive index, $k$, are $10-16 \%$ for values $>10^{-3}$ and $25 \%$ for values $<10^{-3}$. The respective relative uncertainty for the absorption Ångström exponent, $\stackrel{\circ}{a p}_{\text {a }}$ is $20 \%$ (Petzold et al., 2009).

Furthermore, the size distribution of non-volatile aerosol compounds was recorded. For this purpose, three of the CPC and the Grimm OPC were connected to a thermal denuder (TD) heating the aerosol to $250{ }^{\circ} \mathrm{C}$. Heating the aerosol removes volatile material from the mixed particles. The difference between the size distributions of the total and of the non-volatile aerosol allows the investigation of the aerosol mixing state and complements the chemical analyses of collected impactor samples.

Particles were collected by two stage impactors and analysed by scanning electron microscopy (SEM) equipped with energydisperse X-ray detection (EDX) for the elemental analysis of the particles. Details of the applied methods are given by Lieke et al. (2011).

\subsection{Flight strategy}

In the period from 25 to 30 January 2008, a strong Western Sahara Dust outbreak extended from the Western African coast to the Cape Verde Islands. During this episode the airflow from the African coast to Cape Verde was characterized by a strong zonal flow from east to west. This specific meteorological situation allowed for a quasi-Lagrangian study of MD transported from Western Africa across the coastline over Dakar (Dakar airport DKR: $14^{\circ} 44^{\prime} 23^{\prime \prime} \mathrm{N}, 17^{\circ} 29^{\prime} 25^{\prime \prime} \mathrm{W} ; 26 \mathrm{~m}$ a.s.l.) to the Cape Verde islands (Praia airport RAI: $14^{\circ} 55^{\prime} 28^{\prime \prime} \mathrm{N}, 23^{\circ} 29^{\prime} 37^{\prime \prime} \mathrm{W}$; $70 \mathrm{~m}$ a.s.1.).

The flights strategy was set up such that the aircraft was flying from Cape Verde Islands following the $15^{\circ} \mathrm{N}$ meridian towards the African coast. The coastline of Senegal was crossed north of Dakar at an altitude of approximately $9 \mathrm{~km}$ a.s.l. to obtain HSRL data of the Saharan dust layer at the land-ocean transition without major contributions of anthropogenic pollution. Close to the border of Senegal the Falcon left the lidar flight altitude and descended into the MD layer at a distance of approximately $200 \mathrm{~km}$ east of Dakar over rural area, and stayed inside for $25 \mathrm{~min}$ at an altitude of $900 \mathrm{~m}$ a.s.l. The dust was probed in situ upstream of Dakar and over the city area during the approach into DKR. After refuelling the MD loaded boundary layer was probed in situ over the ocean downstream of Dakar. Then the Falcon climbed to the lidar altitude and measured the MD layer from upstream of Dakar over the city area to the ocean. During the ascents to and the descents from the lidar flight altitude, a thin layer of biomass burning aerosol was traversed which extended from 2000 to $3500 \mathrm{~m}$ a.s.l. Figure 1 summarises the entire flight track (graphic insert) and details of the approach into Dakar airport, showing details of sampling which are discussed in the results section.

\subsection{Back-trajectory analysis}

For the interpretation of aerosol in situ measurements, air mass transport analyses by means of trajectory models supply important information about aerosol source regions and the meteorological conditions along the transport pathway. Although precision and availability of the meteorological input data have increased during the last years, single trajectories have position errors in the range of $20 \%$ of the transport distance (Stohl et al., 1998). Trajectory ensembles help to estimate the sensitivity of the calculated transport pathways, even if they do not improve the accuracy as such. In our case study, we applied a flight analysis tool (Hamburger et al., 2010), which is based on the Lagrangian Analysis Tool LAGRANTO developed by Wernli and Davies (1997). A bunch of 100 trajectories is started from a predefined box, which is centred on the starting point. The box has a horizontal radius of $500 \mathrm{~m}$ and a vertical depth of $200 \mathrm{~m}$. Meteorological data used for the trajectory calculation is retrieved from the ECMWF operational archive. The data have a horizontal resolution of $0.225^{\circ} \times 0.225^{\circ}$ and a vertical resolution of 91 levels. Prognostic data $(+3 \mathrm{~h})$ complement the temporal resolution of the operational archive of $6 \mathrm{~h}$. Thus, a temporal resolution of $3 \mathrm{~h}$ can be provided for the trajectory calculation.

\section{Results}

The presentation of results starts with the overall description of the plume properties followed by the discussion of the local circulation patterns because they are essential for the attribution of flight sequences to aerosol types. Then we present the analysis of aerosol microphysical and optical properties. The section closes with the assessment of the impact of aerosol mixing on the chemical composition and thus on the index of refraction. 


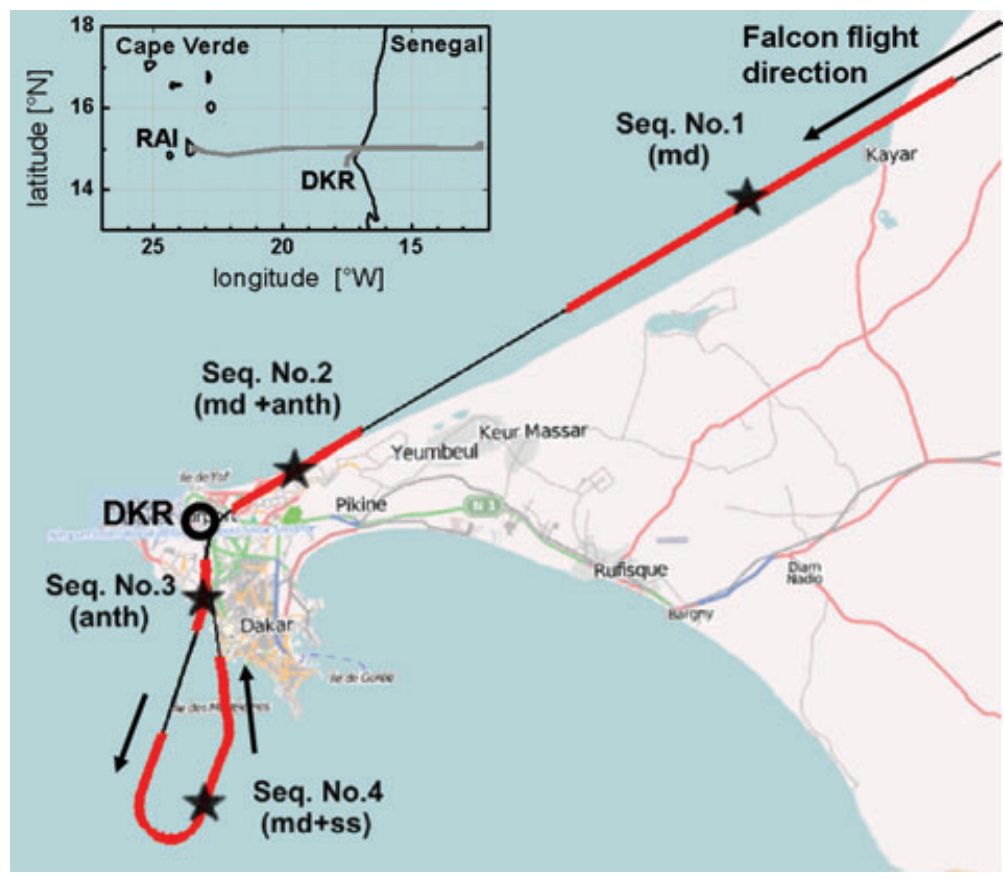

Fig. 1. Map of the region of Dakar including the flight path during the approach to Dakar airport DKR; indicated are the sequences where different aerosol types such as mineral dust (md), mineral dust mixed with anthropogenic pollution (md+anth), anthropogenic pollution (anth) and mineral dust mixed with marine aerosol (md+ss) were encountered. Numbers refer to the sequences given in Table 2. The insert sketches the entire flight pattern from Praia (RAI) to Dakar (DKR) and back.

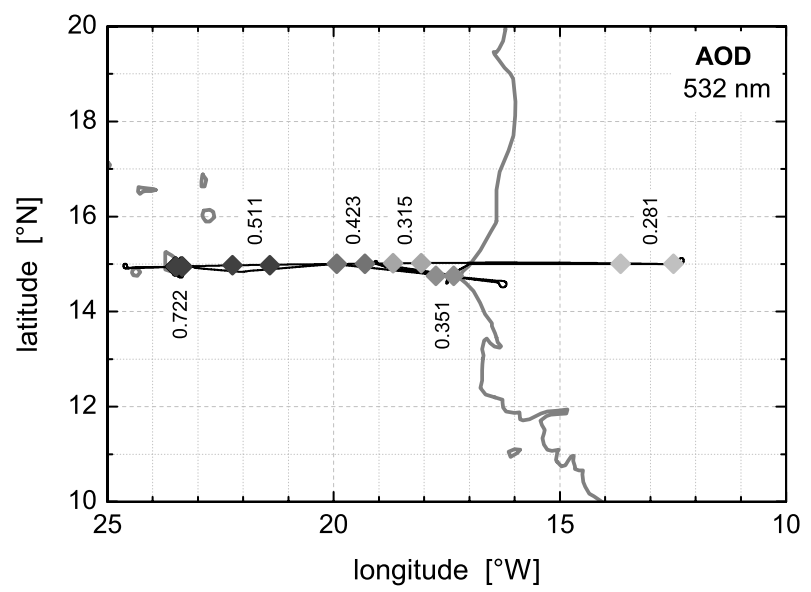

Fig. 2. Flight pattern including aerosol optical depth (AOD) values calculated from selected HSRL profiles at the indicated positions; symbols of same colour represent start and stop times of the HSRL averaging sequence; numbers refer to the average $\mathrm{AOD}$ at the respective positions.

\subsection{MD layer properties}

Figure 2 shows a map of the flight path and the observed AOD data at $532 \mathrm{~nm}$ measured by the HSRL. Detailed values are compiled in Table 1. In all cases, the HSRL extinction profile analysis was restricted to a minimum altitude of $200 \mathrm{~m}$ a.s.l. for excluding ground return effects. The aerosol optical depth of the MD layer varies from $0.423 \pm 0.081$ at approximately $300 \mathrm{~km}$ off the coast to $0.315 \pm 0.057$ at $120 \mathrm{~km}$ off the coast, and finally to $0.281 \pm 0.055$ over land $550 \mathrm{~km}$ away from the coastline. Over the area of Dakar, an AOD of $0.351 \pm 0.045$ is measured which is significantly enhanced compared to the value of 0.281 measured over the rural area east of Dakar. The layer height varies from $1.2 \mathrm{~km}$ over sea to $1.6-1.7 \mathrm{~km}$ over land. The increase in layer height and AOD from the West African coast towards the Cape Verde Islands is confirmed by satellite images of the dust outbreak (http://earthobservatory.nasa.gov/ NaturalHazards/view.php?id = 19569), which shows a clearly visible dust plume extending from about $20^{\circ} \mathrm{W}$ towards the west whereas the area close to Dakar shows less dense dust loadings.

Figure 3 shows the more complex structure of the dust layer over the area of Dakar. Anthropogenic pollution is characterized by high backscatter ratios $>5.5$. The HSRL measurements taken during the overflight over Dakar seem to indicate that the plume evolves from an area which is located approximately $30 \mathrm{~km}$ away from Dakar towards inland. A meteorological analysis which is discussed in the following section demonstrates that this apparent shift of the plume origin is caused by sea breeze circulation. Furthermore, a clearly distinguishable residual of the plume is visible west of Dakar $150 \mathrm{~km}$ off the coast over the ocean. The MD layer and the anthropogenic emissions from the city of Dakar were probed in situ during the approach into and climb-out from Dakar airport; Fig. 1 shows the measurement sequences during the approach.

\subsection{Local circulation patterns}

The general structure of the Dakar plume is determined by the interaction of mesoscale westward flow and a local sea breeze circulation. Figure 3 showing a vertical cross-section of the plume 
Table 1. Location, dust layer height and aerosol optical thickness for selected positions of the dust plume probed during the flights on 29 January 2008 between Praia (Cape Verde) and Dakar (Senegal), minimum height used for the AOT analysis is $200 \mathrm{~m}$ a.s.1.

\begin{tabular}{lccccc}
\hline & Latitude $\left({ }^{\circ} \mathrm{N}\right)$ & Longitude $\left({ }^{\circ} \mathrm{W}\right.$, start $)$ & Longitude $\left({ }^{\circ} \mathrm{W}\right.$, stop $)$ & Layer height (km a.s.1.) & AOD (532 nm) \\
\hline 29aProfile1 & 15.0063 & 19.934 & 19.3107 & 1.41 & $0.423 \pm 0.081$ \\
29aProfile2 & 15.0184 & 18.6859 & 18.0636 & 1.14 & $0.315 \pm 0.057$ \\
29a_Land & 15.0068 & 13.6562 & 12.4905 & 1.68 & $0.281 \pm 0.055$ \\
29c_Dakar & 14.75275 & 17.7413 & 17.3459 & 1.59 & $0.351 \pm 0.045$ \\
29cProfile1 & 14.9785 & 22.2395 & 21.4140 & 1.43 & $0.511 \pm 0.037$ \\
29dPraia1 & 14.9467 & 23.5067 & 23.3823 & 1.18 & $0.722 \pm 0.102$ \\
29ePraia2 & 14.9472 & 23.4895 & 23.3490 & 1.16 & $0.561 \pm 0.095$ \\
29ePraia3 & 14.9472 & 23.4895 & 23.3490 & 1.16 & $0.522 \pm 0.080$ \\
29eProfile1 & 14.753 & 23.3754 & 23.3202 & 1.16 & $0.487 \pm 0.082$ \\
\hline
\end{tabular}

The error refers to the statistical error of the extinction profile.

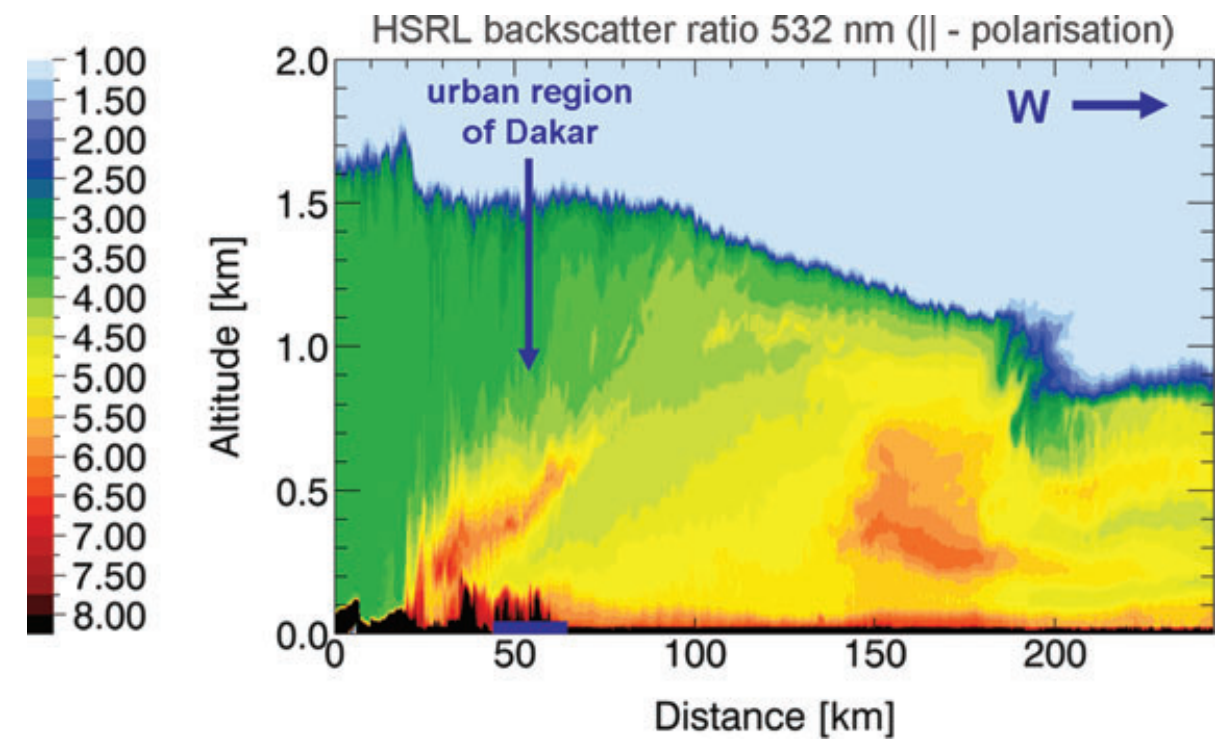

Fig. 3. HSRL cross-section of the Dakar plume mixing into the mineral dust layer; the city of Dakar is situated at $50 \mathrm{~km}$ distance whereas the plume appears to originate from an area $30 \mathrm{~km}$ inland of Dakar; this local shift is caused by sea-breeze circulations (see text for details); at distance $150 \mathrm{~km}$ a residual of the plume is observed. Viewing direction is south, direction to west is indicated.

based on HSRL $532 \mathrm{~nm}$ backscatter ratio indicate stable conditions in the 0-200 m layer above the urban region of Dakar and active convection 10-15 km east of Dakar. West of Dakar in an altitude of $800 \mathrm{~m}$ a.s.l. the plume gets significantly diffused and becomes rarely detectable at all. Because of the strength of the mesoscale flow and the mentioned structure of the HSRL profile, the observed sea breeze is assumed to be a one-way breeze without a return flow during nighttime. Furthermore, the topography of the Dakar peninsular with hills up to $60 \mathrm{~m}$ influences the detailed structure of the sea breeze circulation and the Dakar plume.

ECMWF reanalysis data in Fig. 4 show the wind patterns in 925 and $1000 \mathrm{hPa}$. They indicate calm conditions (missing arrows) together with slight convergence in the lower level and stronger easterly winds in the upper lever above Dakar, which points at a sea breeze circulation that weakens the mesoscale flow near surface and enforces the mesoscale flow in the upper boundary layer.

Meteorological in situ data from the Falcon are shown in Fig. 5 for the approach into Dakar airport. At an altitude of $640 \mathrm{~m}$ a.s.l. the area of Dakar was crossed, causing strong variation of aerosol particle number concentrations. It has to be noted that the maximum number concentration measured at $640 \mathrm{~m}$ a.s.l. coincides with the maximum number concentration measured during the approach to Dakar airport at an altitude of 200 $\mathrm{m}$ a.s.l. This finding backs the HSRL profile shown in Fig. 3, which locates the lofted urban pollution plume over Dakar at the same altitude as we measured it in situ. The potential temperature profile provides evidence for a stable stratified level from 0 to $250 \mathrm{~m}$. Above that layer a well-mixed, statically neutral 


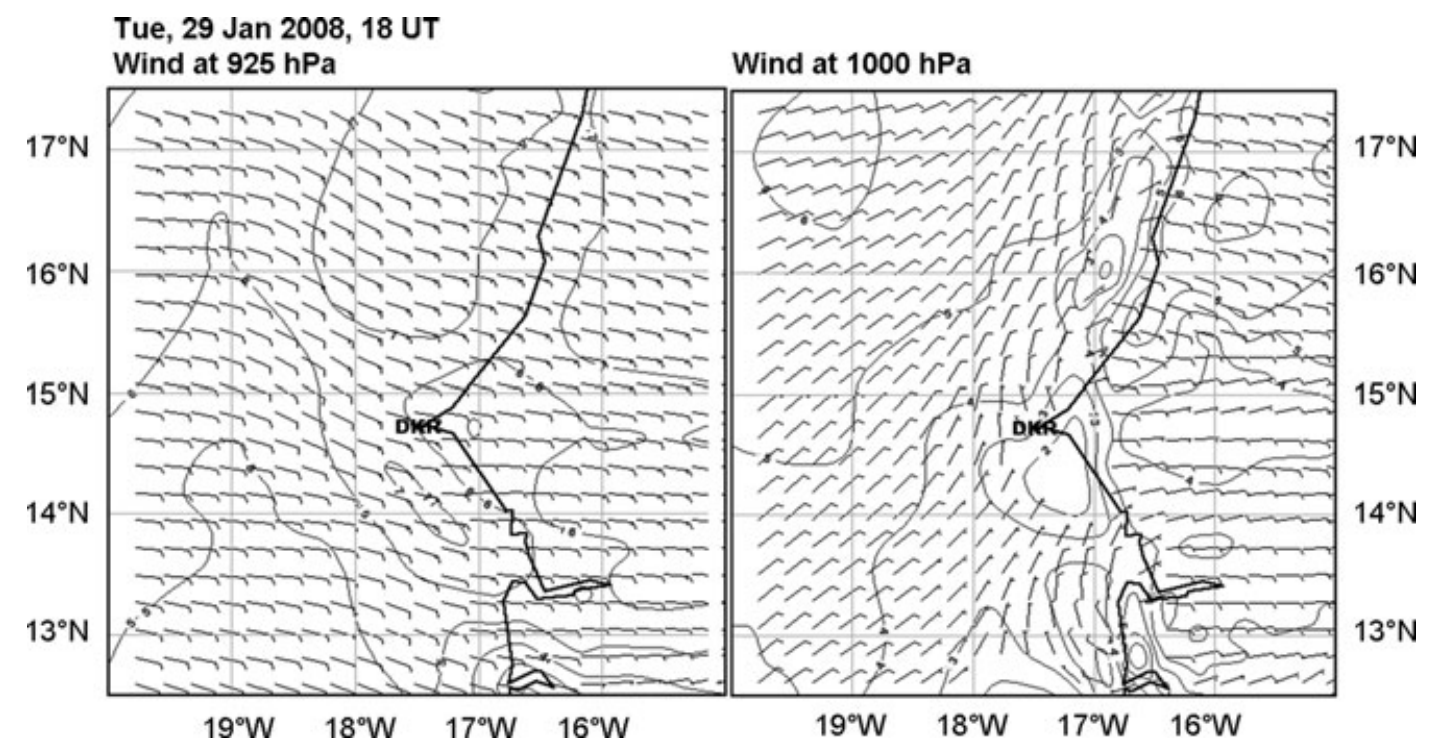

Fig. 4. Horizontal wind fields at $925 \mathrm{hPa}$ (left) and $1000 \mathrm{hPa}$ (right) in the area of Dakar at 29 January 2009.
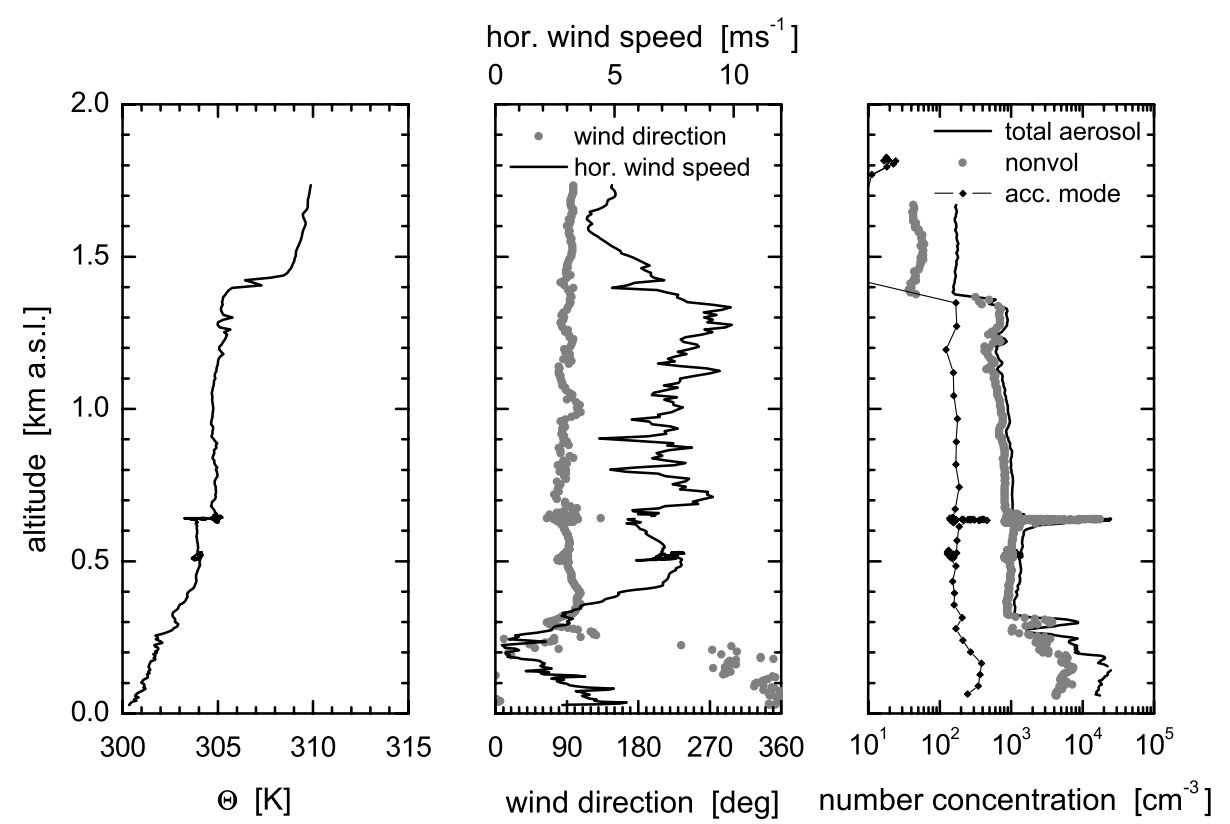

Fig. 5. Vertical profiles of potential temperature $\theta$ (left), horizontal wind speed and wind direction (mid), and of particle number concentrations for total aerosol $\left(d_{\mathrm{p}}>10 \mathrm{~nm}\right)$ non-volatile particles and accumulation mode aerosol $\left(d_{\mathrm{p}}>0.1 \mu \mathrm{m}\right)$ as measured during the approach into Dakar airport

boundary layer indicates the continental origin of these air masses. Strong wind shear as well as large variations in wind speed can be observed from the surface up to about $300 \mathrm{~m}$ a.s.1.

Because of the large variations of all relevant parameters within the lower boundary layer, the ECMWF reanalysis data, which are based on a $0.225^{\circ} \times 0.225^{\circ}$ grid resolution, is forced to contain a certain inaccuracy referring to a realistic estimation of backward trajectories crossing those levels influenced by the sea breeze circulation. Figure 6 shows a result of a trajectory calculation. It is a composition plot of the Falcon flight track (black line) and trajectories starting from the positions where four impactor samples (marked by red stars and numbered FAT_XXX) were taken. Because of the small-scale Dakar plume features we chose a maximum backwards timescale of 24 hours to achieve adequate plots grids, but for different purposes we used considerably larger timescales (see Lieke et al., 2011). Each calculation time step of 30 minute is represented by a single dot in the plot. Approximate plume ageing times listed in Table 2 were obtained from back trajectory analyses. The ageing times refer to the time when the sampled air mass left the coast. 


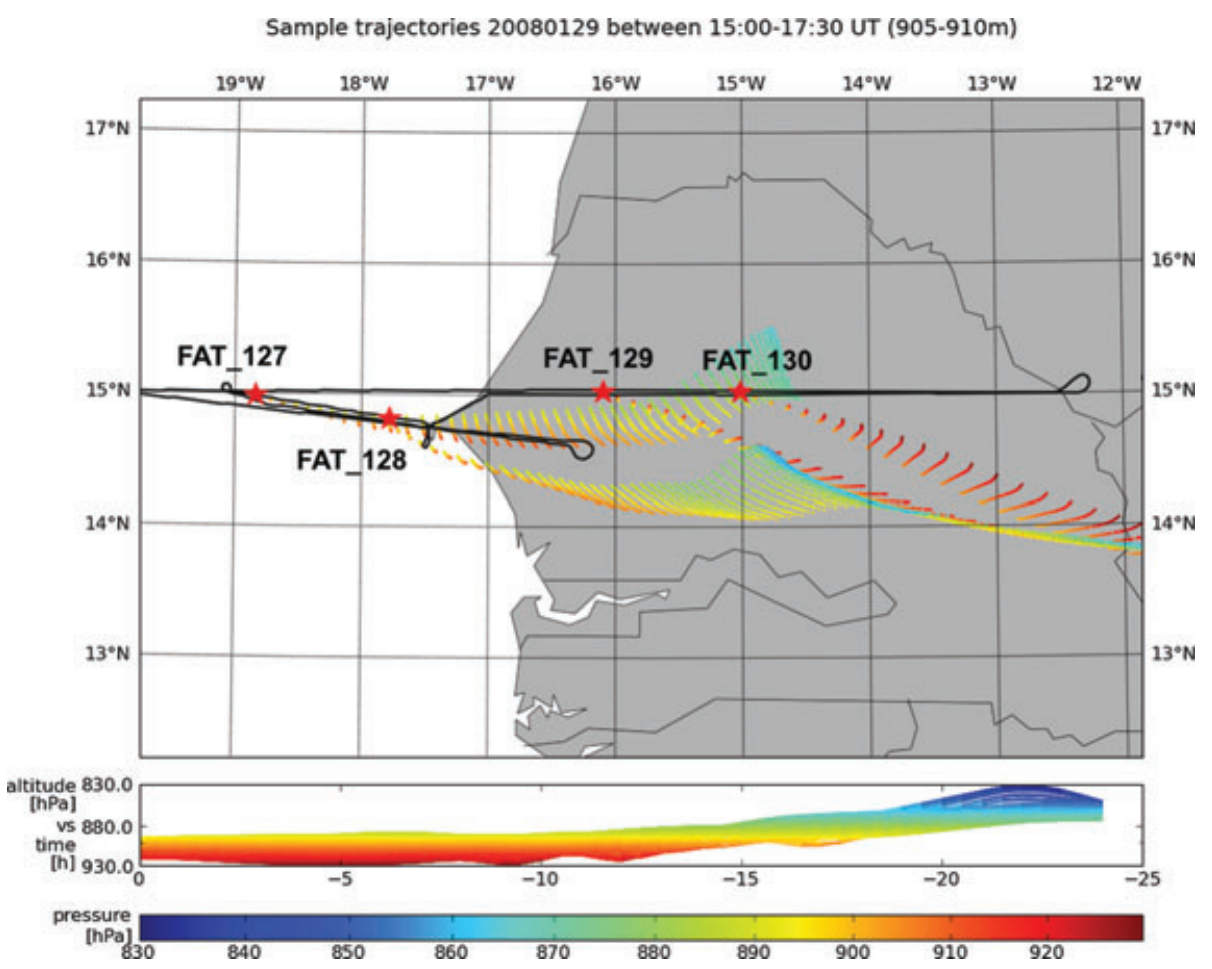

Fig. 6. Back trajectories for impactor filters collected upstream and downstream Dakar; stars indicate the sampling locations; the colour scale indicates the pressure level of the trajectory at the respective time in hours prior to sampling.

Figure 6 and especially trajectory FAT_127 is a good example for both, the advantages and the limit of trajectory considerations within this case study, because in this trajectory plot the bulk of the ensemble crosses the urban region of Dakar, but a certain percentage of trajectories passes Dakar northerly or southerly. As the detailed interpretation of aerosol in situ data is crucially dependent on the exact characterization of the source regions and the structure of the plume, it is worth investigating further effort to get a more precise picture of the circulation pattern. Highresolution numerical modelling of the sea breeze circulation with the MM5 model is part of this work. This work is expected to provide more detailed information on the plume structure and ageing.

\subsection{Particle microphysical properties}

During the approach into Dakar airport, the urban plume was crossed two times with pure MD layer encounters in between. The plume boundaries were very sharp and MD and urban plume were clearly separated. The fine structure of the urban pollution plume emitted from Dakar is shown in Fig. 7. Here we summarize the changes in total aerosol number concentration (N4: $d_{\mathrm{p}}>4 \mathrm{~nm}$; N10: $d_{\mathrm{p}}>10 \mathrm{~nm}$ ), number concentration of nonvolatile particles with $d_{\mathrm{p}}>10 \mathrm{~nm}$ (nonvol N10), the fraction of non-volatile particles, that is the ratio nonvol N10/N10 (crosshatched area), and the PSAP raw signal at $660 \mathrm{~nm}$ for the ap- proach into (left section) and the climb-out from (right section) Dakar airport. The flight altitude is added as thick grey line. The aerosol microphysical and optical properties are compiled in Table 2 for the different aerosol types encountered during the Dakar study. The aerosol-type classification is based on the analysis of the sampling location taken from Fig. 1 combined with back-trajectory analyses.

To start with the vertical distribution of optical properties, Fig. 8 depicts the profiles of extinction (532 nm) based on HSRL data and absorption $(530 \mathrm{~nm})$ over the North Atlantic west of Dakar, over the region east of Dakar, and over the city of Dakar. Besides the different vertical extents of the dust layer over sea and over land we clearly see the significant increase in aerosol absorption in the urban pollution plume by a factor of three; see also Table 2 for detailed values.

Particle number size distributions are presented in Fig. 9 for the dust layer east of Dakar, over the city of Dakar, west of Dakar and east of Praia. No significant differences are observed for the size range $d_{\mathrm{p}}>1 \mu \mathrm{m}$ with respect to their impact on particle optical properties. Largest differences are found for $d_{\mathrm{p}}<$ $0.3 \mu \mathrm{m}$. The increase in the Aitken mode $\left(d_{\mathrm{p}}<0.1 \mu \mathrm{m}\right)$ over land and in particular in the Dakar plume as indicated by the size distributions corresponds to the presence of an externally mixed mode of secondary particles in the aerosol which vanishes during the transport of the dust over sea. We want to point out that the size distributions measured west of Dakar and east of 


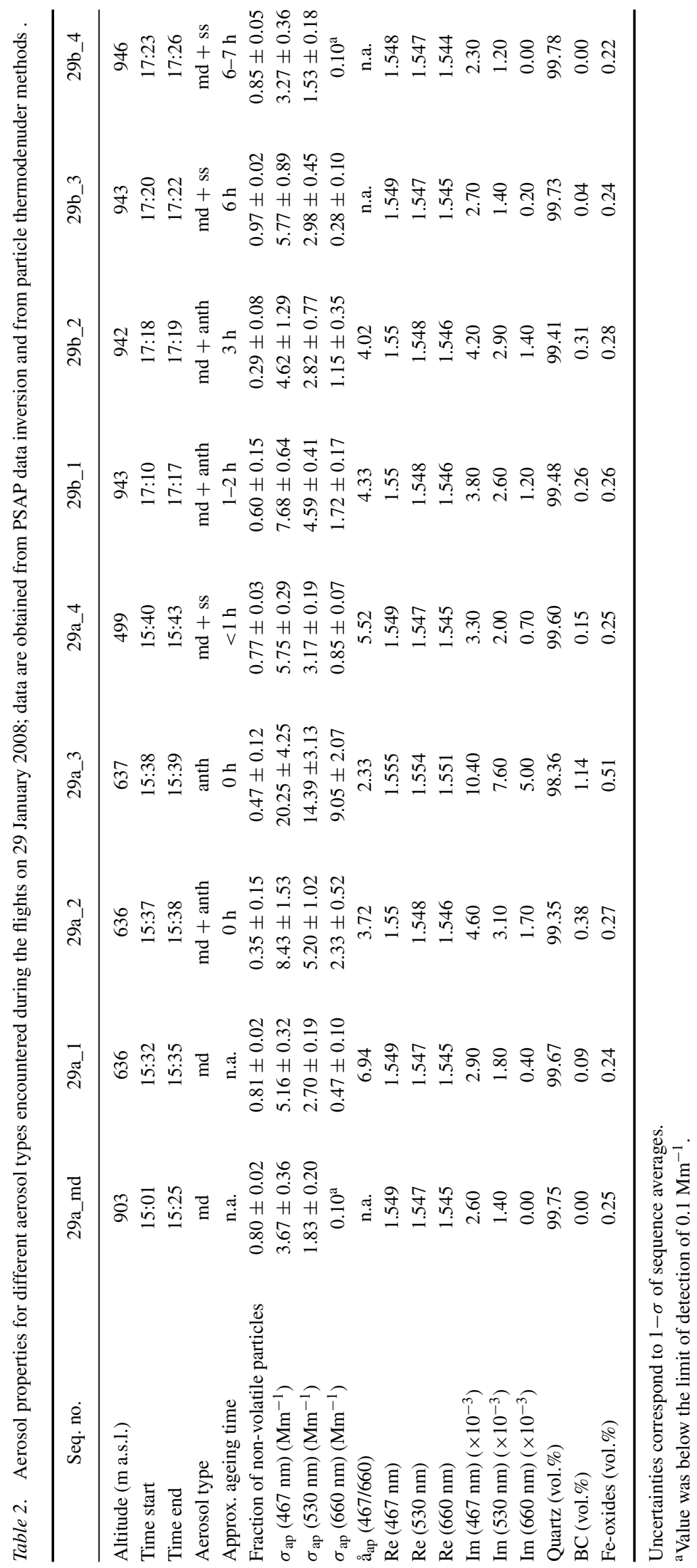




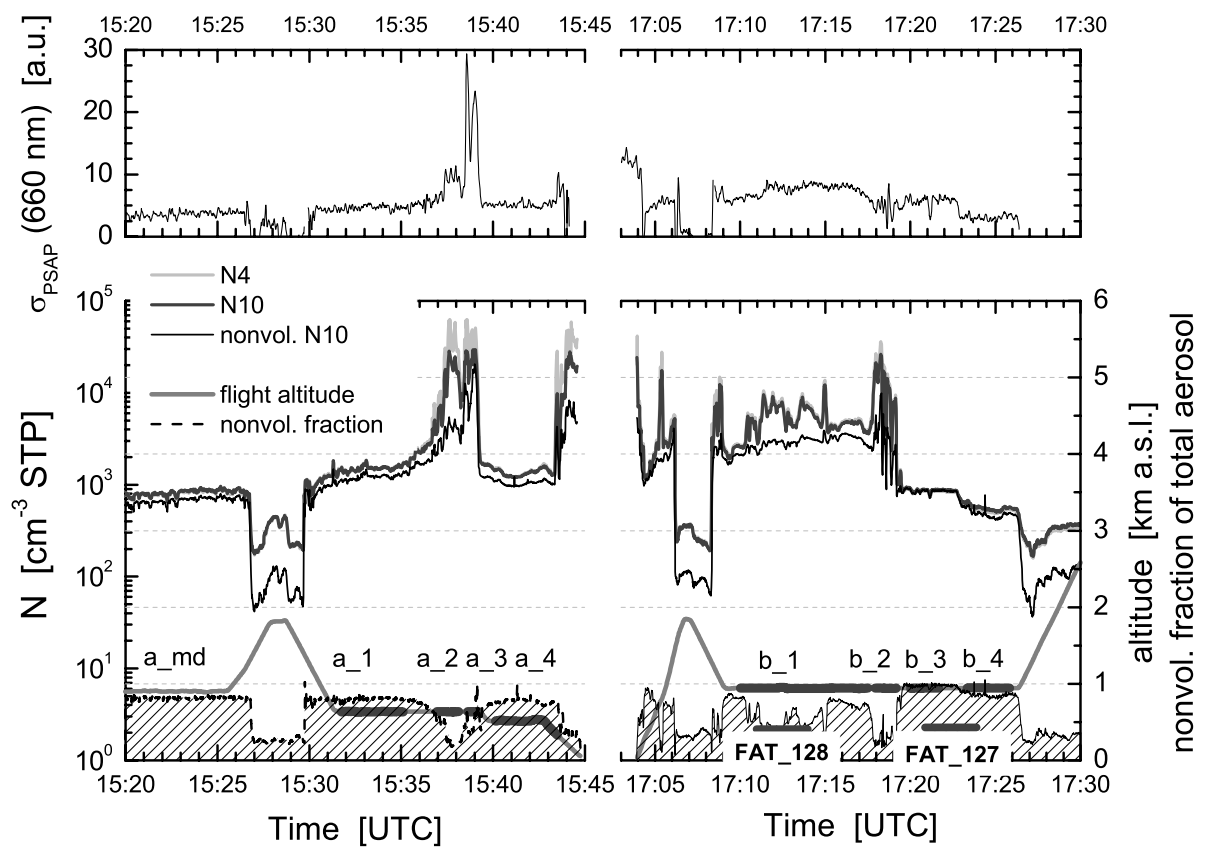

Fig. 7. Top panel: time series of PSAP raw signal at $660 \mathrm{~nm}$. Bottom panel: detailed time series of the approach into Dakar airport (15:30-15:45 UTC), and respective time series of aerosol properties during climb out (17:02-17:30 UTC). Labels for sequences correspond to Table 2 such that 29x_y; sampling sequences for impactor samples FAT_128 and FAT_127 are indicated.

Fig. 8. Profiles of extinction from HSRL and of absorption from PSAP for selected sequences over sea, over land and over the city of Dakar.
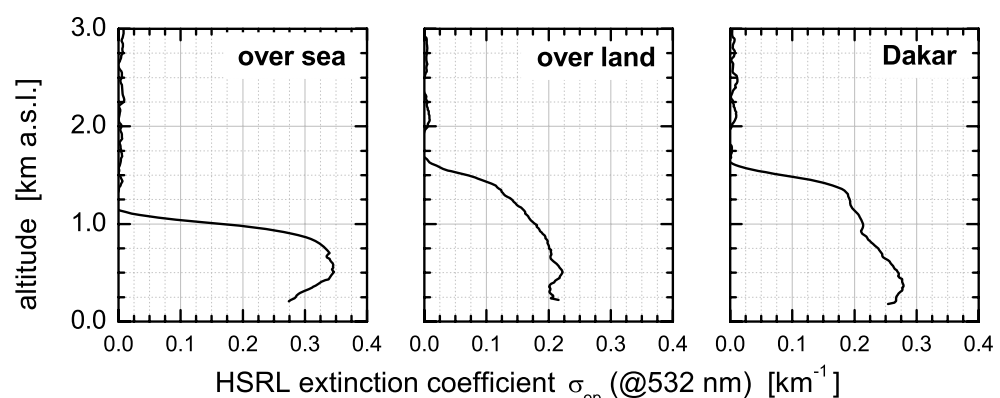

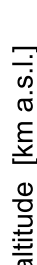
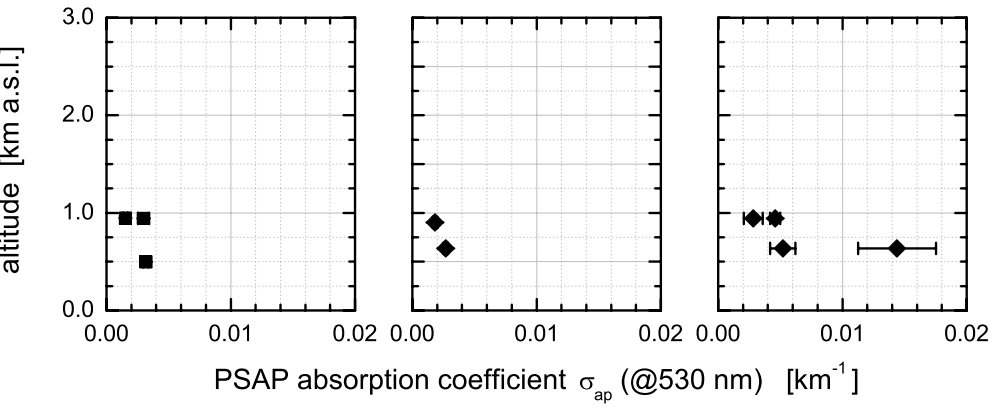

Praia are almost similar although the two sites are separated by a distance of approximately $500 \mathrm{~km}$. This observation suggests that the modification of the aerosol size distribution by atmospheric dilution and processing is completed soon after the air mass has left the coast and no more emissions are mixed in from the surface.

A closer view on the modification of the aerosol size distribution by urban emissions is presented in Fig. 10. Here we show the relative increase in the number concentrations measured in the size channels of the PCASP instrument. As reference case we selected the particle size distribution measured inside the dust layer at a distance $>100 \mathrm{~km}$ east of Dakar. The labels of the size distributions correspond to the sequences indicated in Fig. 7. Upper channel diameters refer to a complex refractive index of $1.545+0.0009 i$. In Fig. 10, we can distinguish three different size ranges: for particles with $d_{\mathrm{p}}>$ 

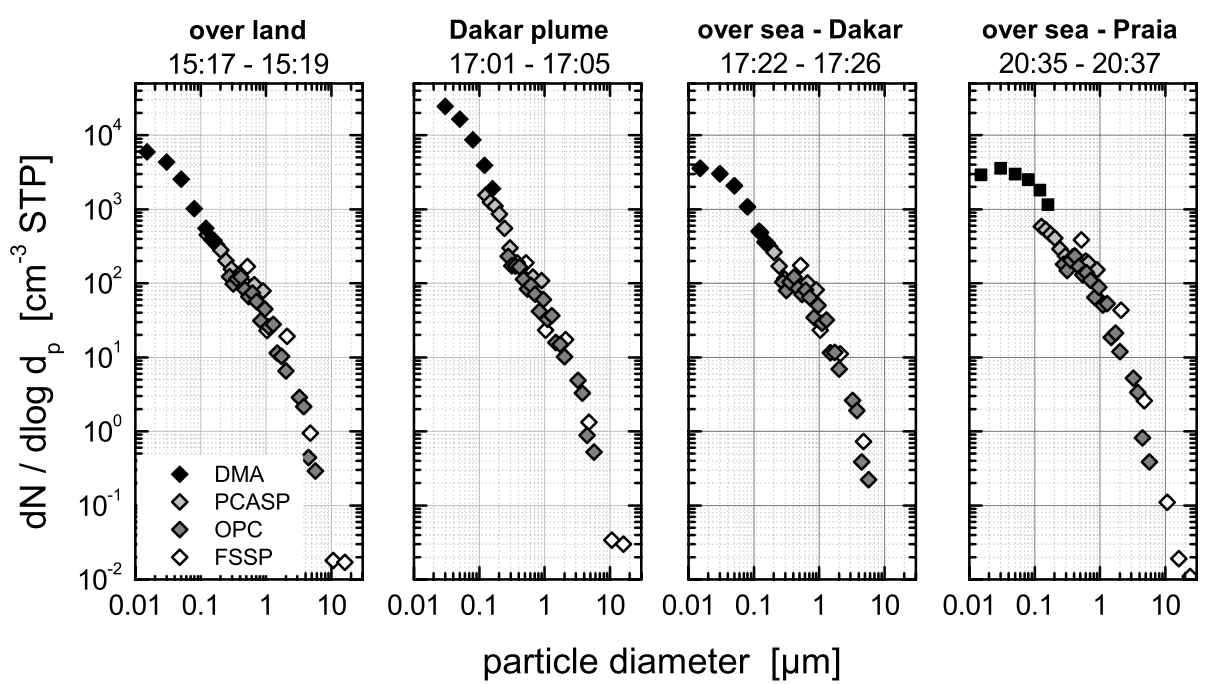

Fig. 9. Particle size distributions measured in the mineral dust layer at $900 \mathrm{~m}$ a.s.l. from left to right: east of Dakar over land, Dakar plume, west of Dakar over sea and east of Praia over sea; times of measurements are given in parentheses as UTC.

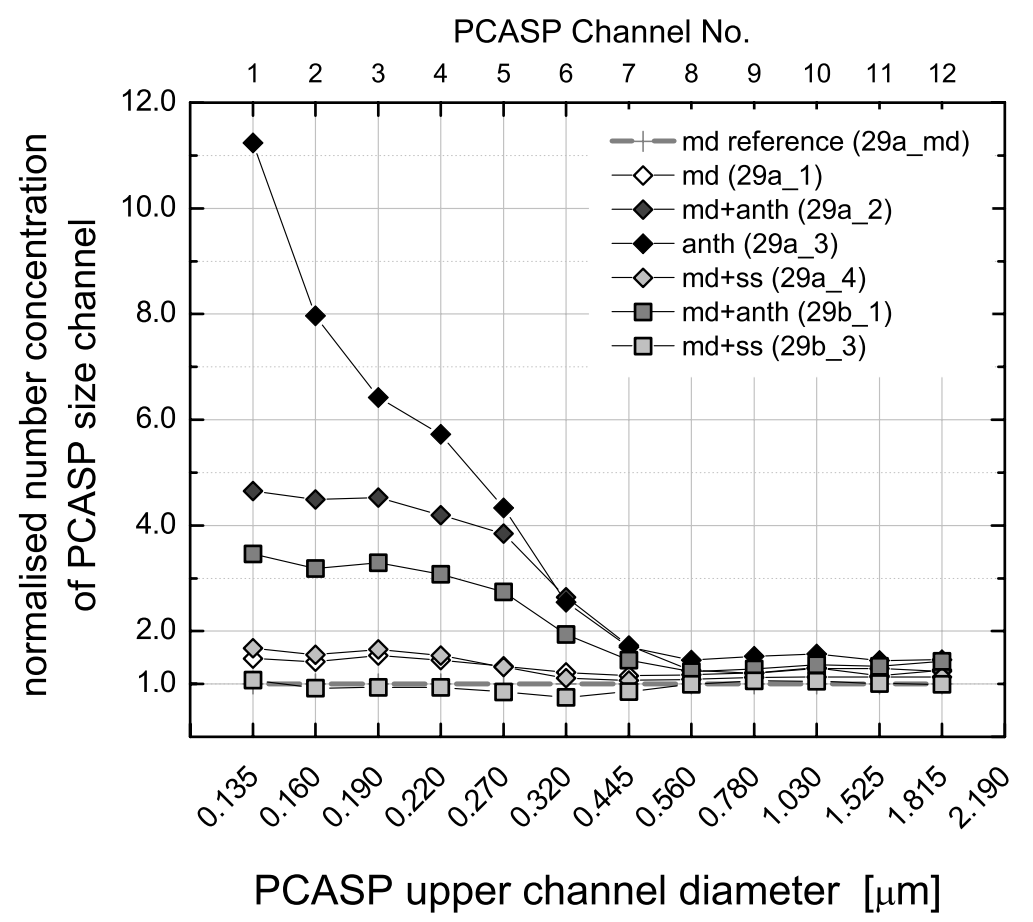

Fig. 10. Relative increase in particle number concentration per PCASP size channel; size spectra are normalised to the spectrum measured east of Dakar over rural area in almost pure mineral dust.

$0.5 \mu \mathrm{m}$, we do not see any significant modification by urban emissions; for particles with $0.2 \mu \mathrm{m}<d_{\mathrm{p}}<0.5 \mu \mathrm{m}$, we see an increase by a factor of 6 compared to unperturbed dust. The strongest effect of the urban emissions is found for particles with $d_{\mathrm{p}}<0.2 \mu \mathrm{m}$. In the size range covered by the PCASP $\left(d_{\mathrm{p}}>0.135 \mu \mathrm{m}\right)$ particle number concentrations are increased by up to a factor of 12 , whereas for sub-100 nm sized particles this increase may be as large as a factor of 60 (Fig. 7). On the other hand, this mode of nanometre-sized particles vanishes first, whereas the enhanced fraction in the size range of
$0.2-0.5 \mu \mathrm{m}$ is still visible in the outflow after $6 \mathrm{~h}$ of atmospheric processing.

Based on the aerosol-type classification from Table 2, we compare in Fig. 11 the non-volatile fraction of the aerosol (left panel) and the contribution of the sub-micrometre aerosol to absorption (right panel, see next section for details). The urban pollution plume is characterized by a strong externally mixed mode of secondary volatile particles which contributes $65-70 \%$ of the total aerosol by number. East of Dakar over rural area, there is already an externally mixed mode of volatile particles 

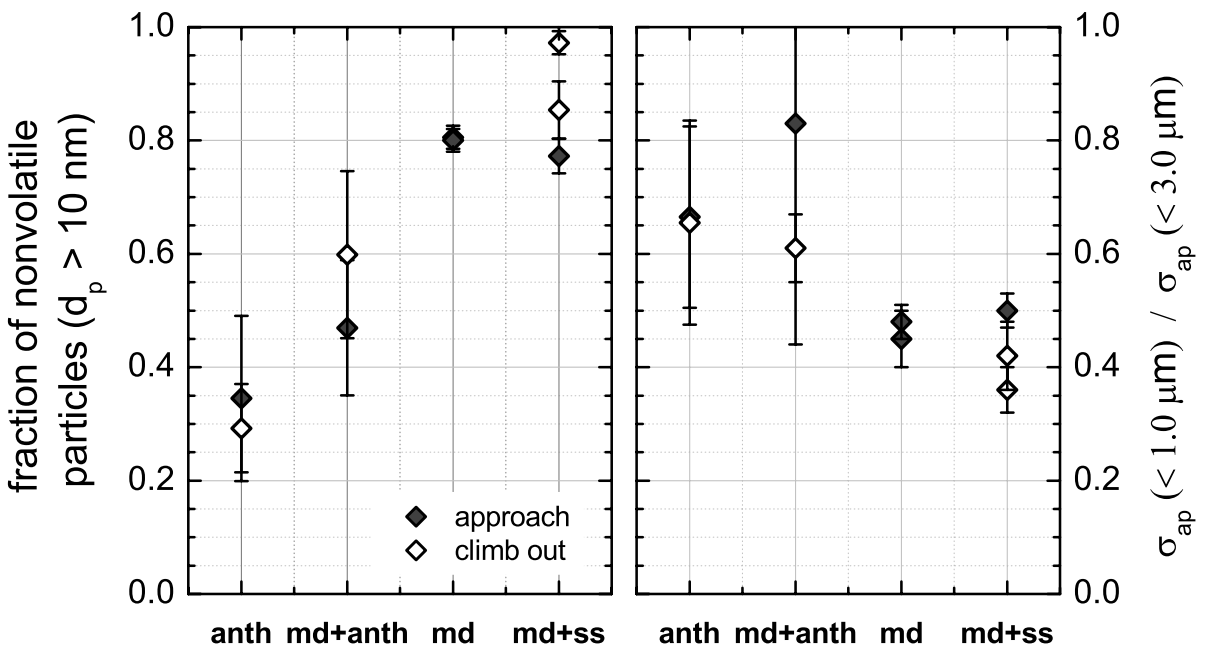

Fig. 11. Left panel: fraction of non-volatile particles of the total aerosol for $d_{\mathrm{p}}>10 \mathrm{~nm}$ for aerosol samples taken at different distances from the source region. Right panel: ratio of sub-micrometre absorption to total absorption for $d_{\mathrm{p}} \leq 3.0 \mu \mathrm{m}$. Aerosol types anthropogenic (anth), mineral dust mixed with anthropogenic (md+anth) and mineral dust mixed with sea salt ( $\mathrm{md}+\mathrm{ss})$ were identified by back trajectory analyses.

present contributing $20 \%$ to the particle number concentration, whereas west of Dakar over sea after 3-6 h of ageing, this mode has almost vanished. We interpret this observation so that over land with its farming activities and even more over the city area with its urban pollution, secondary aerosol particles form from surface gaseous emissions, whereas over the ocean, the supply of condensable gases is strongly reduced and the externally mixed mode of secondary particles is rapidly depleted by coagulation.

\subsection{Particle optical properties}

Revisiting Fig. 11, right panel, sub-micrometre sized particles contribute $65-80 \%$ to aerosol absorption at $530 \mathrm{~nm}$ in the urban pollution plume embedded in the dust layer, whereas in the absence of urban pollution, this fraction is reduced to approximately $40 \%$ for unperturbed dust. These values follow similar trends as data reported by Quinn et al. (2004) for the outflow from China and Korea towards Japan. They found a fraction of $90-94 \%$ in polluted air masses and a fraction of $75 \%$ in MD.
To determine the anthropogenically induced absorption coefficient, the differences in absorption coefficients at $660 \mathrm{~nm}$ are evaluated. In this spectral region, dust is only very weakly absorbing and the observed differences can be attributed entirely to anthropogenic emissions. From background sequences 29a_md, 29a_1,29b_3 and 29b_4, a background absorption coefficient of $0.22 \pm 0.20 \mathrm{Mm}^{-1}$ is calculated (see data in Table 2); for comparison, $\sigma_{\text {ap }}(530 \mathrm{~nm})=2.26 \pm 0.69 \mathrm{Mm}^{-1}$. Subtracting this background value from the absorption measurements conducted in the vicinity of Dakar, the anthropogenic contributions to $\sigma_{\text {ap }}$ $(660 \mathrm{~nm})$ are obtained. Table 3 summarizes the results.

Over the city area urban pollution contributes more than $90 \%$ to aerosol absorption at $660 \mathrm{~nm}$ whereas this fraction decreases to $80 \%$ in the area west of the city over the sea; see Fig. 1 for the location of the respective sampling sequences. For the wavelength of $530 \mathrm{~nm}$ where dust contributes significantly to absorption, the respective fractions are $84 \%$ and $20 \%$. From the fact that for $530 \mathrm{~nm}$, the anthropogenic contribution to absorption (50-84\%) and the contribution of sub-micrometre aerosol to absorption $(\leq 75 \%)$ are almost similar, we conclude that the

Table 3. Anthropogenic contribution to aerosol absorption and respective soot mass concentrations in Dakar; the sequence numbers correspond to the ones shown in Fig. 1.

\begin{tabular}{lccccc}
\hline \multicolumn{1}{c}{ Seq. no. } & 29a_2 & 29a_3 & 29a_4 & 29b_1 & 29b_2 \\
\hline Anthropogenic $\sigma_{\text {ap }}(660)\left(\mathrm{Mm}^{-1}\right)$ & 2.10 & 8.82 & 0.62 & 1.49 & 0.92 \\
Anthropogenic fraction $\sigma_{\text {ap }}(660)(\%)$ & 90 & 98 & 73 & 87 & 80 \\
Anthropogenic fraction $\sigma_{\text {ap }}(530)(\%)$ & 57 & 84 & 29 & 51 & 20 \\
Anthropogenic BC $\left(\mu \mathrm{g} \mathrm{m}^{-3}\right)$ & 0.39 & 1.62 & 0.12 & 0.31 & 0.07 \\
BC mass fraction (\%) SAMUM-1 (Wagner et al., 2009) & 0.17 & 0.71 & 0.05 & 0.14 & 0.03 \\
BC mass fraction (\%) OPAC (Hess et al., 1998) & 0.13 & 0.52 & 0.04 & 0.10 & 0.02 \\
BC mass fraction (\%) PSAP scheme (Petzold et al., 2009) & 0.22 & 0.66 & 0.09 & 0.15 & 0.18 \\
\hline
\end{tabular}




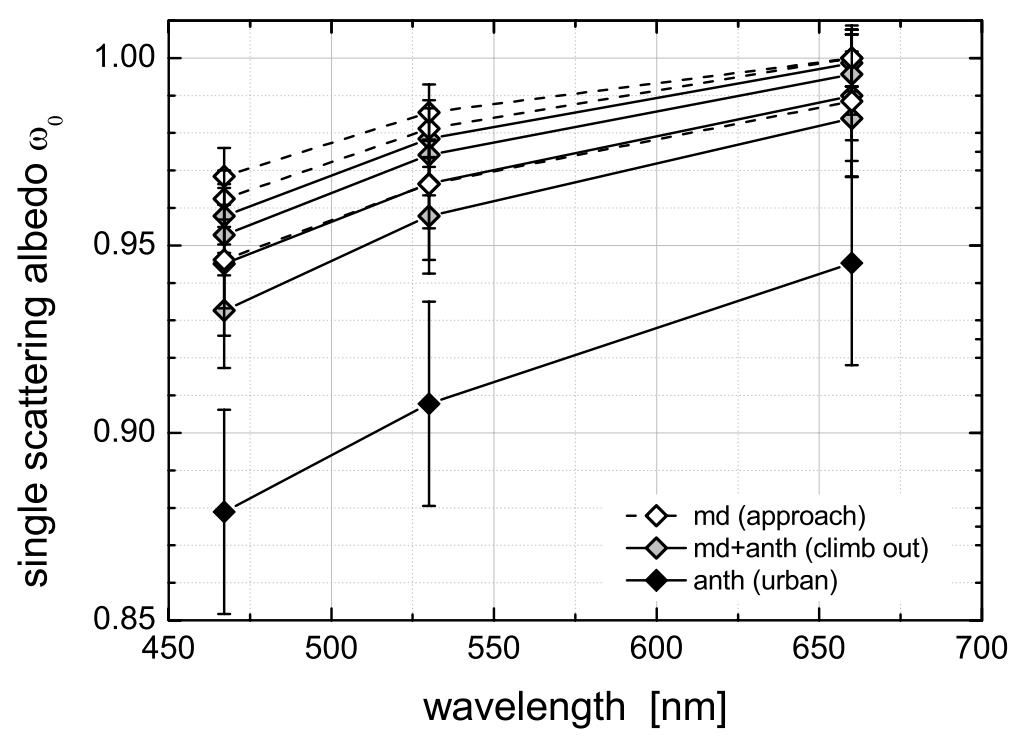

Fig. 12. Singe-scattering albedo $\omega_{0}$ of the sub $3.0 \mu \mathrm{m}$ fraction determined from the PSAP data inversion scheme (Petzold et al., 2009).
$\mathrm{BC}$ particles are confined to $d_{\mathrm{p}}<1.0 \mu \mathrm{m}$ and no internal mixing with coarse dust mode particles has occurred. Potential contributions of organic carbon to absorption are considered negligible at the wavelength of $530 \mathrm{~nm}$ because organic carbon is efficiently absorbing the UV to blue spectral region only.

The wavelength dependence of the absorption coefficient as expressed by the absorption Ångström exponent $\stackrel{\circ}{a p}_{a}=-\ln \left(\sigma_{\text {ap }}(467 \mathrm{~nm}) / \sigma_{\text {ap }}(660 \mathrm{~nm})\right) / \ln (467 \mathrm{~nm} / 660 \mathrm{~nm})$ is in all cases considerably larger than the value of 1.0 which is expected for pure BC. For the Dakar case, MD always dominates the absorption spectral dependence. In contrast, $\stackrel{\circ}{a p}_{\text {values }}$ close to unity were frequently observed in Casablanca during SAMUM-1 although MD was present as well in the urban atmosphere. Absorption coefficients at $530 \mathrm{~nm}$ are of similar magnitude in Dakar (14.4 \pm 3.1$)$ and in Casablanca (12.8 \pm 2.2$)$ while

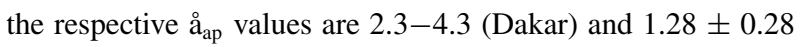
(Casablanca, 18 samples).

The values of the single-scattering albedo $\omega_{0}$, which we obtained from the applied PSAP data inversion scheme (Petzold et al., 2009), are summarized in Fig. 12. For a wavelength of $530 \mathrm{~nm}$, we found $\omega_{0}>0.96$ for MD and $\omega_{0}=0.908 \pm 0.018$ for aerosol collected in the Dakar plume. Our $\omega_{0}$ values agree very well with data reported for the Southeast Asia (Quinn et al., 2004). We remind the reader that these single-scattering values refer to the size range $d_{\mathrm{p}} \leq 3.0 \mu \mathrm{m}$.

\subsection{Particle chemical composition and refractive index}

Particle chemical composition was derived from impactor samples by means of an elemental analysis using SEM-EDX, see Lieke et al. (2011) for details. Figure 13 summarizes the abundance of mineralogical compounds by number for the impactor samples collected during the flight missions for the size fraction $<0.5 \mu \mathrm{m}$. For all cases, silicates are the most abundant component, and externally mixed carbonaceous (soot) particles were found. In the samples FAT_127 and FAT_128 which were collected over the sea, few chloride-containing particles were found.

From the dust-dominated cases, sample FAT_127 shows the highest fraction of carbonaceous particles in the sub-500 nm part although the sample was collected at some distance away from the coast. In contrast, sample FAT_128 which was collected closer to the coast showed the lowest fraction of carbonaceous particles in the sub-500 nm fraction. For comparison, in another sample collected in a thin lofted biomass-burning aerosol layer at $2300 \mathrm{~m}$ a.s.1. which originated from Central African savannah fires, a large fraction of carbonaceous agglomerates was found. However, PSAP analyses yield a BC volume fraction of $8.4 \%$ and an aerosol absorption Ångström exponent of 1.20 for this biomass-burning aerosol. An extensive overview over particle optical properties measured during SAMUM-2 is given by Weinzierl et al. (2011).

For particles larger than $0.5 \mu \mathrm{m}$ in diameter (projection diameter), no carbonaceous particles were observed, and the aerosol is always MD dominated. Thus, the SEM analysis of the impactor samples provide strong evidence that carbonaceous (soot) particles were present exclusively as external mixtures, and that carbonaceous particles already present in the dust layer east of Dakar originate most likely from biomass burning regions.

The anthropogenic contribution to absorption (Table 3) was used to calculate the anthropogenic BC mass concentration by applying the mass-specific absorption coefficients of $7.5 \mathrm{~m}^{2} \mathrm{~g}^{-1}$ $(530 \mathrm{~nm})$ and $6.25 \mathrm{~m}^{2} \mathrm{~g}^{-1}(660 \mathrm{~nm})$ from Bond and Bergstrom (2006). Respective values for BC mass concentrations are also listed in Table 3. Applying a mass-specific extinction efficiency of $0.87 \mathrm{~m}^{2} \mathrm{~g}^{-1}(\lambda=530 \mathrm{~nm}$; Wagner et al., 2009) to the extinction profiles measured by the HSRL, they can be converted into dust mass concentration profiles. Assuming an average extinction 


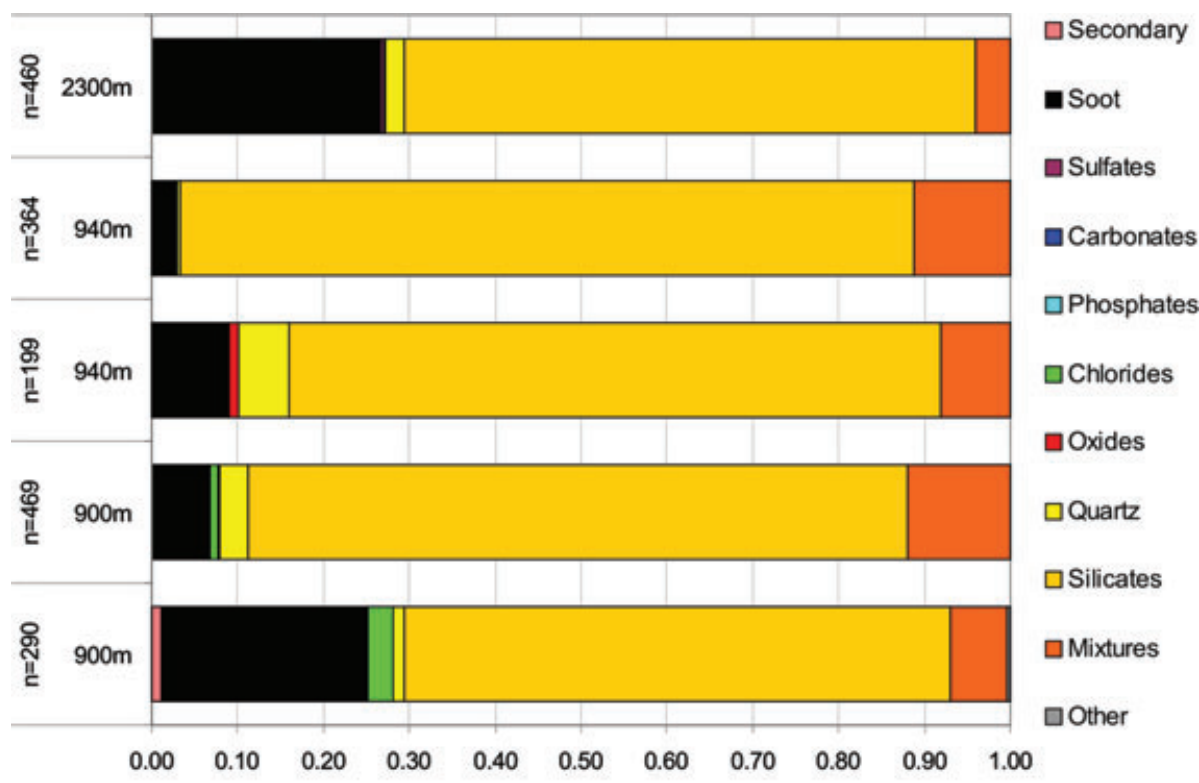

Fig. 13. Number fraction of particles of specific chemical composition in the size range smaller than $500 \mathrm{~nm}$ in diameter; impactor sample numbers are FAT_131, FAT_130, FAT_129, FAT_128 and FAT_127 (from top to bottom).

of $0.2 \mathrm{~km}^{-1}$ (Fig. 8), an average dust mass concentration of $230 \mu \mathrm{g} \mathrm{m}^{-3}$ is obtained. Using the OPAC value (Hess et al., 1998) of $0.64 \mathrm{~m}^{2} \mathrm{~g}^{-1}$ for the mass-specific extinction efficiency of dust, the respective mass concentration is $313 \mu \mathrm{g} \mathrm{m}^{-3}$. These values can be used as lower and upper estimates for the dust mass concentrations in Dakar.

Assuming that the dust mass concentration in Dakar is dominated by the dust advected from the East, we calculated the $\mathrm{BC}$ mass fraction of the Dakar aerosol from the values listed in Table 3 and compared it to the data obtained from the PSAP inversion scheme. The values compiled in Table 3 show that the BC mass fraction of the total aerosol was below $1 \%$ for all cases. They also indicate that the PSAP inversion data agree fairly well with the fractions estimated from the dust extinction and form the anthropogenic BC fraction, in particular when the fact is considered that the PSAP measures only the sub-3.0 $\mu \mathrm{m}$ fraction whereas the HSRL detects extinction from particles of any size.

The impact of this small amount of $\mathrm{BC}$ on the complex index of refraction is shown in Fig. 14. Adding less than $1 \%$ by mass of $\mathrm{BC}$ to $\mathrm{MD}$ increases the imaginary part of the refractive index at $530 \mathrm{~nm}$ by more than a factor of 6 . Although this is a significant impact on the light absorbing properties of dust, the imaginary part of the complex refractive index is still within the natural variability of MD from different sources; see for example Petzold et al. (2009).

\section{Discussion and conclusion}

Optical properties of dust mixed with anthropogenic emissions from the urban area of Dakar, Senegal, were determined from

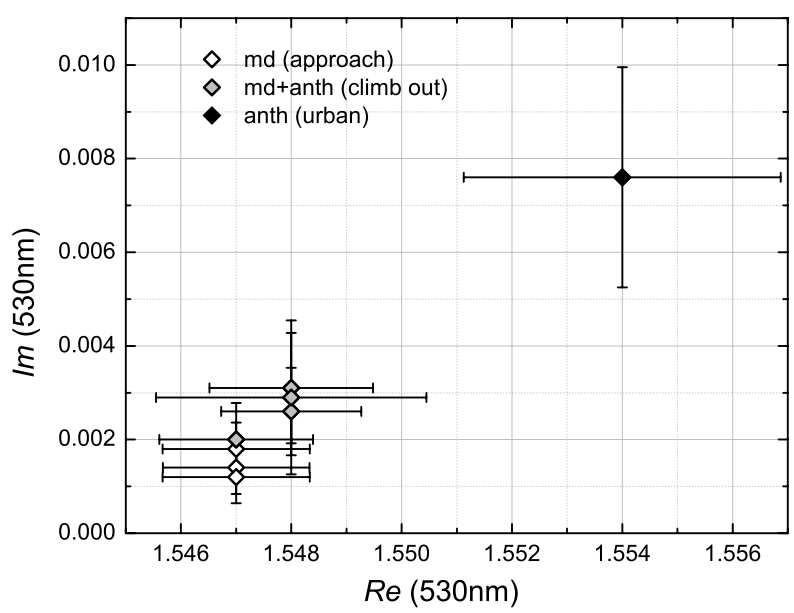

Fig. 14. Real part ( $x$-axis) and imaginary part ( $y$-axis) of the complex refractive index at $530 \mathrm{~nm}$ for mineral dust (md), dust-black carbon mixtures (md + anth), and aerosol dominated by anthropogenic emissions (anth), collected in the vicinity of Dakar.

the difference between average values found upstream the source region in dust plumes not affected by urban emissions, and values determined from samples taken over the urban area of Dakar. We found a clear signature of the Dakar plume in both data from an HSRL and from in situ data.

The aerosol affected by urban pollution showed a significantly increased fraction of volatile particles which were externally mixed. Particle number concentrations were enhanced by more than one order of magnitude in the size range $<0.3 \mu \mathrm{m}$. In the urban area, the aerosol light absorption at $660 \mathrm{~nm}$ was enhanced by a factor of 10 compared to MD upstream of the 


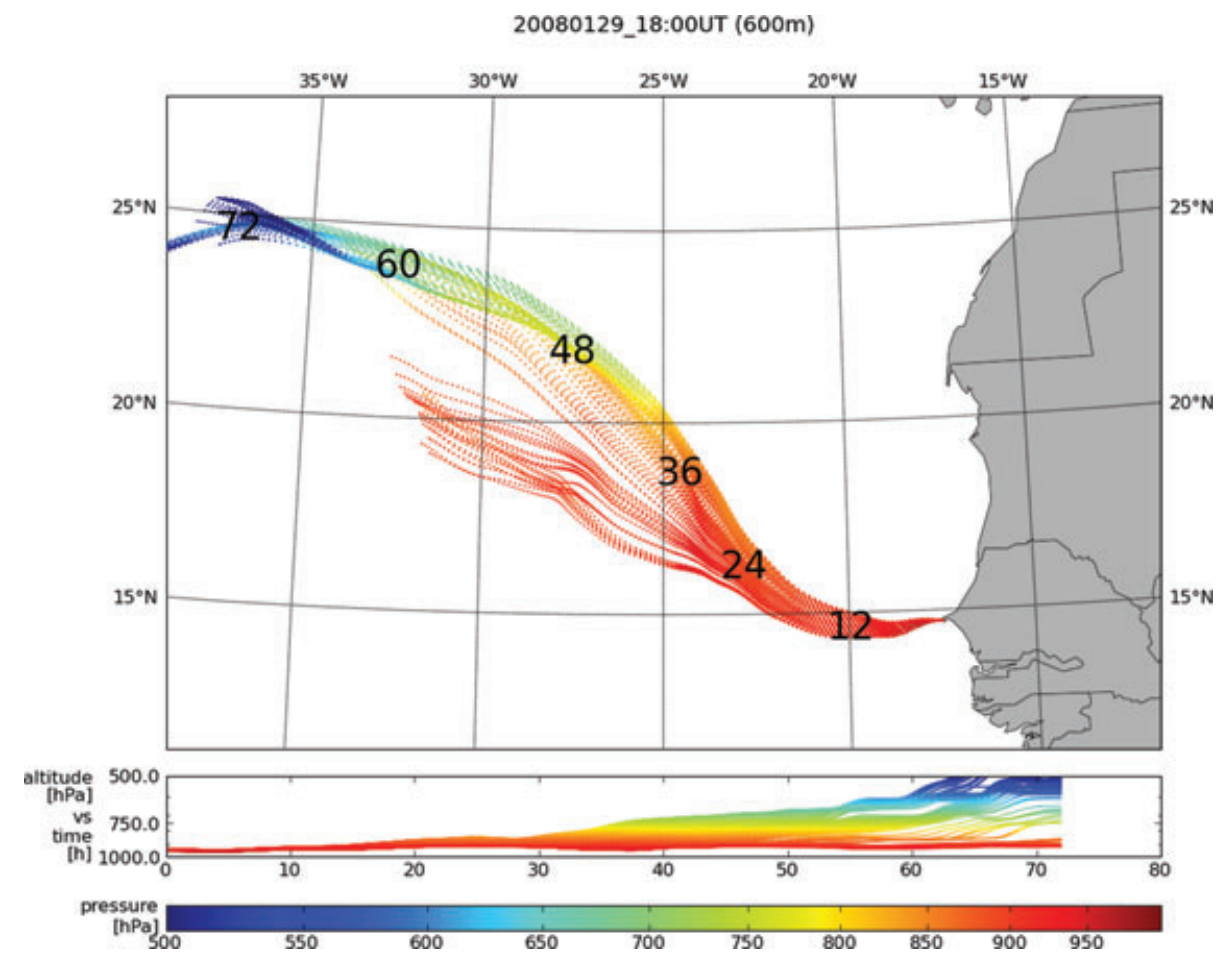

Fig. 15. Forward trajectories of the Dakar plume started at $600 \mathrm{~m}$ a.s.l. over the city of Dakar; as in Fig. 6, the colour scale indicates the pressure level of the trajectory at the respective time in hours after emission.

source. In the green where MD is stronger absorbing than in the red, absorption was still enhanced by a factor of five. HSRL extinction data at $532 \mathrm{~nm}$ indicate an increase of AOD from 0.28 to 0.3 over land and over sea off Dakar to 0.35 over the area of Dakar. This increase by $16 \%$ is statistically significant. Comparing the increase in extinction to the increase in absorption clearly demonstrates that MD completely dominates the optical properties of the aerosol even over a strong source region for anthropogenic pollution as the city of Dakar.

$\mathrm{BC}$ agglomerates (soot) were observed mainly in the sub$500 \mathrm{~nm}$ fraction by electron microscopy. This indicates external mixture of $\mathrm{MD}$ and $\mathrm{BC}$ particles. Back trajectories of samples show that even after $6 \mathrm{~h}$ of transport $\mathrm{BC}$ agglomerates are still externally mixed. Internal mixtures of $\mathrm{BC}$ agglomerates with MD were not detected (Lieke et al., 2011). BC aerosol was only observed to mix with secondary sulphate. The coarse particles $(d>0.5 \mu \mathrm{m})$ were dominated by silicates.

The prevalence of externally mixed carbonaceous agglomerates in the dry atmosphere of Western Africa is also reported for biomass burning particles (Formenti et al., 2008; Rajot et al., 2008; Hand et al., 2010) from the AMMA studies. Chou et al. (2008) have shown that biomass burning aerosols in dust layers are essentially found in the $0.1-0.6 \mu \mathrm{m}$ diameter range, whereas MD particles are seldomly found below $0.4 \mu \mathrm{m}$ diameter. With respect to mixing with $\mathrm{MD}, \mathrm{BC}$ from anthropogenic sources and biomass burning particles seem to behave similarly.
During the strong dust event of 25-30 January 2008, the $\mathrm{BC}$ emissions from the city of Dakar contributed about $1 \%$ of mass to the total aerosol. The impact of this amount of $\mathrm{BC}$ on the radiative properties of MD, however, seems to be of local importance only. Figure 15 illustrates the transport and diffusion of the Dakar plume after release at $600 \mathrm{~m}$ a.s.l.; the forward trajectory release height reflects the altitude to which the plume is lifted by sea breeze circulation. At the same altitude the plume residual was observed $150 \mathrm{~km}$ off the coast over the Atlantic Ocean; see Fig. 3 for details. The plume is then transported westward at low altitudes $>900 \mathrm{hPa}(<1.0 \mathrm{~km})$ inside the dust layer (Fig. 8) for about $18 \mathrm{~h}$ over a distance larger than $600 \mathrm{~km}$ before being mixed into the free troposphere. During the lowlevel transport, any characteristic signatures such as externally mixed BC or externally mixed volatile Aitken mode particles have been vanished and the plume becomes indistinguishable from the embedding dust layer (Lieke et al., 2011; Weinzierl et al., 2011).

Over the source area the imaginary part of the refractive index is increased by a factor of six, but still remains within the natural variability of MD from various sources. Similarly, even over the source region the wavelength dependence of aerosol absorption is dominated by the MD fraction. This observation is completely different to measurements performed during SAMUM-1 in the dust-loaded atmosphere of the city of Casablanca, Morocco (Petzold et al., 2009). There we found absorption Ångström 
exponent values close to unity which are characteristic for an aerosol dominated by small-sized BC agglomerates.

\section{Acknowledgments}

The SAMUM research group was funded by the Deutsche Forschungsgemeinschaft (DFG) under grant number FOR 539. We are grateful to the DLR Flight Operations for their excellent support during the preparation of the field study and during the research flights. Furthermore, the extensive support of the flight activities out of Praia Airport by the Cape Verde authorities, and in particular by Praia airport operations, air traffic control, TACV and the national meteorological service INMG are gratefully acknowledged. Without their outstanding contributions this work would not have been possible.

\section{References}

Ansmann, A., Petzold, A., Kandler, K., Wendisch, M., Müller, D. and co-authors. 2011. Saharan Mineral Dust Experiments SAMUM-1 and 1 SAMUM-2: what have we learned? Tellus $B$, this issue.

Bergstrom, R. W., Pilewskie, P., Pommier, J., Rabbette, M., Russell, P. B. and co-authors. 2004. Spectral absorption of solar radiation by aerosols during ACE-Asia. J. Geophys. Res. 109, doi:10.1029/2003JD004467.

Bond, T. C. and Bergstrom, R. W. 2006. Light absorption by carbonaceous particles: an investigative review. Aerosol Sci. Technol. 40, 27-67.

Chou, C., Formenti, P., Maille, M., Ausset, P., Helas, G. and coauthors. 2008. Size distribution, shape, and composition of mineral dust aerosols collected during the African Monsoon Multidisciplinary Analysis Special Observation Period 0: dust and biomass-burning experiment field campaign in Niger, January 2006. J. Geophys. Res. 113, doi:10.1029/2008JD009897.

Clarke, A. D., Shinozuka, Y., Kapustin, V. N., Howell, S., Huebert, B. and co-authors. 2004. Size distributions and mixtures of dust and black carbon aerosol in Asian outflow: physiochemistry and optical properties. J. Geophys. Res. 109, doi: 10.1029/2003JD004378.

Esselborn, M., Wirth, M., Fix, A., Tesche, M. and Ehret, G. 2008. Airborne high spectral resolution lidar for measuring aerosol extinction and backscatter coefficients. Appl. Opt. 47, 346-358.

Esselborn, M., Wirth, M., Fix, A., Weinzierl, B., Rasp, K. and co-authors. 2009. Spatial distribution and optical properties of Saharan dust observed by airborne high spectral resolution lidar during SAMUM 2006. Tellus 61B, 131-143.

Feldpausch, P., Fiebig, M., Fritzsche, L. and Petzold, A. 2006. Measurement of ultrafine aerosol size distributions by a combination of diffusion screen separators and condensation particle counters. J. Aerosol Sci. 37, 577-597.

Formenti, P., Rajot, J. L., Desboeufs, K., Caquineau, S., Chevaillier, S. and co-authors. 2008. Regional variability of the composition of mineral dust from western Africa: results from the AMMA SOP0/DABEX and DODO field campaigns. J. Geophys. Res. D: Atmos. 113, doi:10.1029/2008JD009903.

Forster, P., Ramaswamy, V., Artaxo, P., Berntsen, T., Betts, R. and coauthors. 2007. Changes in atmospheric constituents and in radiative forcing. Climate Change 2007: The Physical Science Basis. Contribution of Working Group I to the Fourth Assessment Report of the Intergovernmental Panel on Climate Change.

Fuller, K. A., Malm, W. C. and Kreidenweis, S. M. 1999. Effects of mixing on extinction by carbonaceous particles. J. Geophys. Res.Atmos. 104, 15941-15954.

Hamburger, T., McMeeking, G., Minikin, A., Birmili, W., Dall'Osto, M. and co-authors. 2010. Overview of the synoptic and pollution situation over Europe during the EUCAARI-LONGREX field campaign. Atmos. Chem. Phys. Discuss. 10, 19129-19174.

Hand, V. L., Capes, G., Vaughan, D. J., Formenti, P., Haywood, J. M. and co-authors. 2010. Evidence of internal mixing of African dust and biomass burning particles by individual particle analysis using electron beam techniques. J. Geophys. Res.-Atmos. 115, doi:10.1029/2009jd012938.

Haywood, J. M., Francis, P., Osborne, S., Glew, M., Loeb, N. and coauthors. 2003. Radiative properties and direct radiative effect of Saharan dust measured by the C-130 aircraft during SHADE: 1 . Solar spectrum. J. Geophys. Res. 108, doi:10.1029/2002JD002687.

Haywood, J. M., Francis, P. N., Glew, M. D. and Taylor, J. P. 2001. Optical properties and direct radiative effect of Saharan dust: a case study of two Saharan dust outbreaks using aircraft data. J. Geophys. Res. 106, 18417-18430.

Hess, M., Koepke, P. and Schult, I. 1998. Optical properties of aerosols and clouds: the software package OPAC. Bull. Am. Met. Soc. 79, 831-844.

Kandler, K., Benker, N., Bundke, U., Cuevas, E., Ebert, M. and coauthors. 2007. Chemical composition and complex refractive index of Saharan mineral dust at Izana, Tenerife (Spain) derived by electron microscopy. Atmos. Environ. 41, 8058-8074.

Lieke, K., Kandler, K., Scheuvens, D., Emmel, C., Glahn, C. V. and co-authors. 2011. Particle chemical properties in the vertical column based on aircraft observations in the vicinity of Cape Verde islands. Tellus 63B, this issue.

Parungo, F., Nagamoto, C., Zhou, M.-Y., Hansen, A. D. A. and Harris, J. 1994. Aeolian transport of aerosol black carbon from China to the ocean. Atmos. Environ. 28, 3251-3260.

Petzold, A., Rasp, K., Weinzierl, B., Esselborn, M., Hamburger, T. and co-authors. 2009. Saharan dust refractive index and optical properties from aircract-based observations during SAMUM 2006. Tellus 61B, 118-130.

Putaud, J. P., Van Dingenen, R., Dell'Acqua, A., Raes, F., Matta, E. and co-authors. 2004. Size-segregated aerosol mass closure and chemical composition in Monte Cimone (I) during MINATROC. Atmos. Chem. Phys. 4, 889-902.

Quinn, P. K., Coffman, D. J., Bates, T. S., Welton, E. J., Covert, D. S. and co-authors. 2004. Aerosol optical properties measured on board the Ronald H. Brown during ACE-Asia as a function of aerosol chemical composition and source region. J. Geophys. Res. 109, doi:10.1029/2003JD004010.

Rajot, J. L., Formenti, P., Alfaro, S., Desboeufs, K., Chevaillier, S. and co-authors. 2008. AMMA dust experiment: an overview of measurements performed during the dry season special observation period (SOP0) at the Banizoumbou (Niger) supersite. J. Geophys. Res.Atmos. 113, doi:10.1029/2008jd009906.

Shi, Z., Shao, L., Jones, T. P., Whittaker, A. G., Lu, S. and co-authors. 2003. Characterization of airborne individual particles collected in an 
urban area, a satellite city and a clean air area in Beijing, 2001. Atmos. Environ. 37, 4097-4108.

Sokolik, I. N. and Toon, O. B. 1996. Direct radiative forcing by anthropogenic airborne mineral aerosols. Nature 381, 681-683.

Song, C. H., Maxwell-Meier, K., Weber, R. J., Kapustin, V. and Clarke, A. 2005. Dust composition and mixing state inferred from airborne composition measurements during ACE-Asia C130 Flight \# 6. Atmos. Environ. 39, 359-369.

Stohl, A., Hittenberger, M. and Wotawa, G. 1998. Validation of the Lagrangian particle dispersion model FLEXPART against large-scale tracer experiment data. Atmos. Environ. 32, 4245-4264.

Trochkine, D., Iwasaka, Y., Matsuki, A., Yamada, M., Kim, Y. S. and co-authors. 2003. Mineral aerosol particles collected in Dunhuang, China, and their comparison with chemically modified particles collected over Japan. J. Geophys. Res.-Atmos. 108, doi:10.1029/2002jd003268.

Virkkula, A. 2010. Correction of the calibration of the 3-wavelength particle soot absorption photometer (3 PSAP). Aerosol Sci. Technol. 44, 706-712.

Virkkula, A., Ahlquist, N. C., Covert, D. S., Arnott, W. P., Sheridan, P. J. and co-authors. 2005. Modification, calibration and a field test of an instrument for measuring light absorption by particles. Aerosol Sci. Technol. 39, 68-83.

Wagner, F., Bortoli, D., Pereira, S., Costa, M., Silva, A. M. and co-authors. 2009. Properties of dust aerosol particles trans- ported to Portugal from the Sahara desert. Tellus 61B, 297306.

Weinzierl, B., Petzold, A., Esselborn, M., Wirth, M., Rasp, K. and coauthors. 2009. Airborne measurements of dust layer properties, particle size distribution and mixing state of Saharan dust during SAMUM 2006. Tellus 61B, 96-117.

Weinzierl, B., Sauer, D., Esselborn, M., Petzold, A., Veira, A. and co-authors. 2011. Microphysical and optical properties of dust and tropical biomass burning aerosol layers in the Cape Verde regionan overview of the airborne in situ and lidar measurements during SAMUM-2. Tellus 63B, this issue.

Wernli, H. and Davies, H. C. 1997. A lagrangian-based analysis of extratropical cyclones. I: The method and some applications. Q. J. R. Meteorol. Soc. 123, 467-489.

Yang, M., Howell, S. G., Zhuang, J. and Huebert, B. J. 2009. Attribution of aerosol light absorption to black carbon, brown carbon, and dust in China-interpretations of atmospheric measurements during EASTAIRE. Atmos. Chem. Phys. 9, 2035-2050.

Zhang, D., Iwasaka, Y., Matsuki, A., Ueno, K. and Matsuzaki, T. 2006. Coarse and accumulation mode particles associated with Asian dust in southwestern Japan. Atmos. Environ. 40, 1205-1215.

Zhang, D. Z., Zang, J. Y., Shi, G. Y., Iwasaka, Y., Matsuki, A. and co-authors. 2003. Mixture state of individual Asian dust particles at a coastal site of Qingdao, China. Atmos. Environ. 37, 38953901. 